\title{
Effect of active control on the preservation of manuscripts in historic libraries
}

\author{
Umut Çağırgan ${ }^{\mathrm{a}}$, Assoc. Prof. Dr. Zeynep Durmuş Arsan ${ }^{\mathrm{b} *}$ and Prof. Dr. Gülden Gökçen Akkurt ${ }^{\mathrm{c}}$ \\ a Department of Architecture, Izmir Institute of Technology, Izmir, Turkey \\ $b$ Department of Architecture, Izmir Institute of Technology, Izmir, Turkey \\ c Department of Energy Systems Engineering, Izmir Institute of Technology, Izmir, Turkey
}

\begin{abstract}
Historic libraries were built to house paper-based collections with cultural heritage values. A balanced indoor climate is required to preserve these collections against the agents of deterioration. This study examines the indoor climate of historic Tire Necip Paşa Library and chemical degradation risk of manuscripts in two periods: pre- and post-restoration work. Indoor air temperature and relative humidity of the library were monitored for one year in 2014-2015 and 2019-2020. The riskiest months, i.e. May to October, determined in pre-restoration, were reanalyzed post-restoration. Then LM and eLM calculations were made for chemical risk assessment of manuscripts. Calculation results show that the risk of chemical degradation is minimized. The majority of results indicate a low risk of chemical degradation.

Peer-review under the responsibility of the organizing committee of the ICMB21.
\end{abstract}

Keywords: Historic library; Manuscript preservation; Indoor climate; Chemical degradation; Risk assessment; Temperature; Relative humidity

\begin{tabular}{|ll|}
\hline Nomenclature \\
$\mathrm{T}$ & Temperature $\left[{ }^{\circ} \mathrm{C}\right]$ \\
$\mathrm{RH}$ & Relative humidity $[\%]$ \\
$\mathrm{LM}$ & Lifetime multiplier \\
$\mathrm{eLM}$ & Equivalent lifetime multiplier \\
$\mathrm{E}_{\mathrm{a}}$ & Activation energy $[\mathrm{kJ} / \mathrm{mol}]$ \\
$\mathrm{R}$ & Gas constant $[\mathrm{J} / \mathrm{molK}]$ \\
\hline
\end{tabular}

\section{Introduction/Background}

Historic libraries were built to house valuable paper-based collections of recorded information. The collections with high cultural heritage value require particularly balanced indoor climates to protect them against the agents of deterioration. Several architectural and mechanical solutions can be implemented to provide this balanced indoor climate, but the library should also be monitored regularly after the interventions to ensure the continuity of required preservation conditions.

Tire Necip Paşa Library in Izmir-Turkey, housing over 1000 manuscripts, was the case library of past researches on the subjects of mechanical, chemical and biological degradation risk assessment [1,2,3]. This study examines the indoor climate of historic building and chemical degradation risk of manuscripts after it underwent a restoration process in the period of 2015-2016. A HVAC system was installed to provide the required preservation conditions of manuscripts. Before the active control, the library had free-flow ventilation with no heating/cooling system, and manuscripts were under the risk of chemical degradation in warmer periods due to high diurnal fluctuations. Conversely it is known that the deterioration process is slower in environments with lower temperatures and moisture content [4].

The library conditions were investigated by monitoring the indoor and outdoor T and RH during six months in two different periods: pre- and post-restoration process. The aim is to find out if HVAC system installation had a positive impact on the indoor microclimate in terms of preservation of manuscripts.

\section{Methodology}

T and RH measurements conducted during May, June, July, August, September and October of 2015 and 2020 are taken into account, since they were found out to be the high-risk months in terms of chemical degradation according to the 2014-2015 measurements [3]. Two HOBO U-12 data loggers were located in the manuscript zone and outside of the case library.

To assess the risk of chemical degradation, the indicators of Lifetime Multiplier (LM) and equivalent Lifetime Multiplier (eLM) are calculated. LM compares the measured indoor T and $\mathrm{RH}$ values as pairs to the set-point environmental conditions of $20^{\circ} \mathrm{C}$ and $50 \%$. While $\mathrm{LM}_{\mathrm{i}}$ is the specific lifetime multiplier at point $\mathrm{i}$, eLM covers a wider period with taking the average of reciprocal values of LM which increases the impact of worse conditions. The equations used to calculate LM (Eq.(a)) and eLM (Eq.(b)) can be seen below [5].

(a) $\mathrm{LM}_{\mathrm{i}}=\left(50 \% / \mathrm{RH}_{\mathrm{i}}\right)^{1.3} \mathrm{x}^{\mathrm{Ea} / \mathrm{R}((1 /(\mathrm{Ti}+273.15))-(1 / 293.15))}$

(b) $\mathrm{eLM}=1 /\left(1 / \mathrm{n} \times\left(\sum_{\mathrm{x}=1}^{\mathrm{n}}\left(1 /\left(\left(50 \% / \mathrm{RH}_{\mathrm{i}}\right)^{1.3} \mathrm{x} \mathrm{e}^{\mathrm{Ea} / \mathrm{R}((1 /(\mathrm{Ti}+273.15))-(1 / 293.15))}\right)\right)\right)\right.$

*Corresponding author. +905327082052 .

(C) The Author( $\dot{s})$. This is an open access article distributed under the terms of the Creative Commons Attribution License (CC BY) 4.0 https:// creativecommons.org/licenses/by/4.0/, which permits unrestricted use, distribution and reproduction in any medium, provided the original 


\section{ICMB21}

$\mathrm{E}_{\mathrm{a}}$ is taken as $100 \mathrm{~kJ} / \mathrm{mol}$ for cellulose degradation and $\mathrm{R}$ is taken as $8.314 \mathrm{~J} / \mathrm{molK}$. A LM value below 0.75 means high risk; above 1 means low risk; and in-between means medium risk of chemical degradation. For eLM a value below 0.75 means high risk; between 0.75-1 means potential risk; between 1-1.7 means some risk; between 1.7-2.2 means good; and above 2.2 means ideal $[3,5]$.

\section{Results}

Measurement results of 2015 for six months show that $\mathrm{T}$ ranges between $19.8^{\circ} \mathrm{C}$ and $34.1^{\circ} \mathrm{C}$, while $\mathrm{RH}$ varies between $26 \%$ and $62 \%$. The 2020 measurement results remarkably differ that $\mathrm{T}$ ranges between $17.7^{\circ} \mathrm{C}$ and $25.7^{\circ} \mathrm{C}$, while $\mathrm{RH}$ varies between $50 \%$ and $63 \%$. The comparative graphs of $\mathrm{T}$ and $\mathrm{RH}$ values in Fig. 1 convey the impact of newly installed HVAC system in providing a more stable indoor climate with minimal fluctuations.

(a)

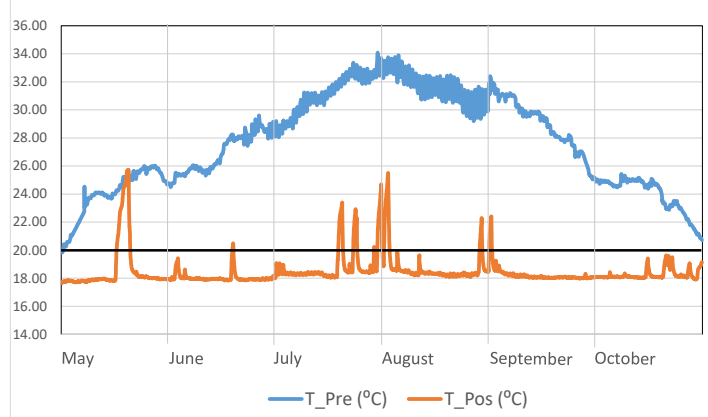

(b)

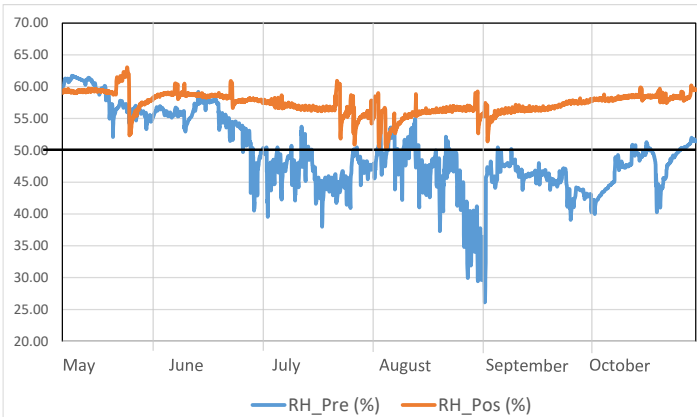

Figure 1. Temperature (a) and relative humidity (b) values of pre-restoration (Pre) and post-restoration (Pos)

According to 2015 measurements, calculated LM values change between 0.15 and 0.87 for six months, while they vary between 0.34 and 1.16 in 2020. Fig. 2 indicates that almost all the LM values of 2015 signify a high risk of chemical degradation. Yet the majority of 2020's LM values point out to low risk of chemical degradation except short periods when the HVAC system was under maintenance. The eLM values of pre- and post-restoration periods are 0.33 and 1.02, respectively. The former means high risk, while the latter refers to some risk.

\section{Discussion and Conclusion}

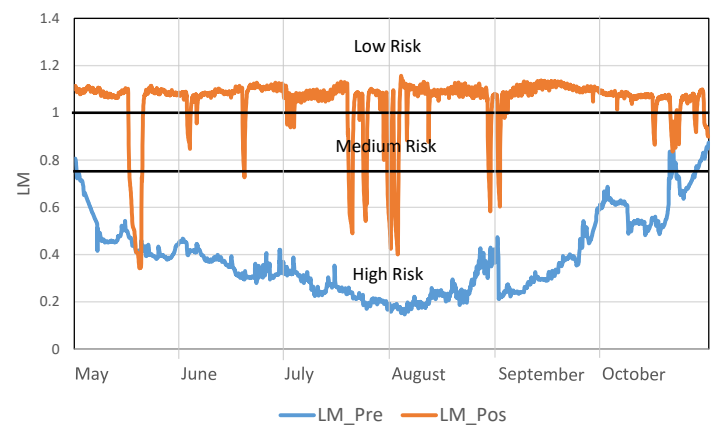

Figure 2. Lifetime multiplier values of pre-restoration (Pre) and post-restoration (Pos)

The T, RH, LM and eLM comparisons on the risky months representing pre- and post-restoration periods indicate that the HVAC system enabled to achieve a more stable indoor environment with a remarkably low risk of chemical degradation except short periods for the maintenance of the system.

While for this study's scope, the six months with most chemical degradation risk are chosen, an assessment which covers all 12 months of a year is undoubtedly needed to make an accurate and complete analysis of the indoor microclimate of the library.

\section{References}

[1] Coşkun T., Şahin C.D., Gülhan O., Arsan Z.D., and Akkurt G.G. 2018. Ventilation Strategies for the Preventive Conservation of Manuscripts in the Necip Paşa Library, Izmir, Turkey. Elsevier Inc.

[2] Coşkun, Turgay, Özcan Gülhan, Cem Doğan Şahin, Zeynep Durmuş Arsan, and Gülden Gökçen Akkurt. 2017. "The Effect of Spatial Interventions on Historic Buildings' Indoor Climate (Case Study: Tire Necip Paşa Library, Izmir-Turkey).” Energy Procedia 133 (October): $358-66$.

[3] Sahin, Cem Doğan, Turgay Coşkun, Zeynep Durmuş Arsan, and Gülden Gökçen Akkurt. 2017. "Investigation of Indoor Microclimate of Historic Libraries for Preventive Conservation of Manuscripts. Case Study: Tire Necip Paşa Library, İzmir-Turkey.” Sustainable Cities and Society 30 (April): 66-78.

[4] Derluyn, H., H. Janssen, J. Diepens, D. Derome, and J. Carmeliet. 2007. "Hygroscopic Behavior of Paper and Books." Journal of Building Physics 31 (1): 934.

[5] Silva, Hugo Entradas, Fernando M.A. Henriques, Telma A.S. Henriques, and Guilherme Coelho. 2016. "A Sequential Process to Assess and Optimize the Indoor Climate in Museums.” Building and Environment 104 (August): 21-34. 